\title{
Analysis of Crimping Forming Experiments
}

\author{
Ying $\mathrm{Gao}^{1, a}$, Lifeng Fan ${ }^{2, b}$, Huajun Yan ${ }^{1, c}$
}

${ }^{1}$ College of Material Science and Engineering, Hebei University of Science and Technology, Shijiazhuang, 050000, China

\author{
${ }^{2}$ Transportation of Institute, Inner Mongolia University, Hohhot,010021, China \\ aemail:gaoyingch@sina.com, bemail:ysufanlifeng@foxmail.com, cemail: yanhj22@163.com
}

Keywords: Crimping; Large Diameter Longitudinal Welded Pipe; Experiment

\begin{abstract}
Large diameter longitudinal welded pipe is the main form of energy transport, and has a wide application in the transportation field of oil and gas. In this paper, crimping forming experiment for large diameter longitudinal welded pipe was introduced, and the relationships between forming stroke, crimping width, step length and bending angle, forming force were obtained. The influence of process parameters on crimping forming of longitudinal welded pipe was discussed. The result has a good guiding role for large diameter welded pipe production.
\end{abstract}

\section{Introduction}

With the rapid development of the petroleum, natural gas and other energy pipeline construction, the demand for large diameter longitudinal welded pipe increases in the industrial traffic intensive areas, river area, big drop area or the earthquake region and submarine pipeline. JCO progressive multi-step molding is one of the typical forming processes of large diameter longitudinal welded pipe in industrial production. As the first process during the JCO forming process, plate edge bending, named as crimping, is one of the most important processes in the welded pipe production line. Bases on the crimping characteristics of longitudinal welded pipe, crimping experiments were performed, in which the experiment model was reduced 3 times comprising to the production crimping model. The relationship between bending springback angle, crimping angle, forming force and other process parameters are discussed. The results have instructive significance on the crimping process.

\section{Crimping forming Experiment}

Analogy is an exploratory and creative method in materials mechanics experiment. With the feature of the similar stress - strain curves material with X80, Q235A was chosen as the experimental material. The chemical compositions of Q235A are shown in table 1. The main mechanics parameters of Q235A measured by the tensile test are shown in table 2. Tensile specimens and tensile results are shown in Figure 1. Crimping die assembly consists of seven parts, such as bending punch, bending die, punch base plate, die base plate, pressure sensor, displacement sensor, and the feeding and clamping plate, which are shown in Fig. 2. The punch radius of base circle is $101.6 \mathrm{~mm}$, involute terminated angle is 88 degrees. The arc radius of the die is $183.3 \mathrm{~mm}$.

The dimension of initial sheet is $210 \mathrm{~mm} \times 300 \mathrm{~mm} \times 4.75 \mathrm{~mm}$. The experimental equipment is four column universal hydraulic machine with the model of YT32-315, whose main technical parameters can be seen in table 3 .

Table 1 Q235A chemical composition

\begin{tabular}{cccccc}
\hline $\begin{array}{c}\text { Compositio } \\
\text { n }\end{array}$ & C & Mn & Si & P & S \\
\hline Content & $\mathbf{0 . 1 2} \sim 0.20$ & $0.30 \sim 0.7$ & $<0.30$ & $<0.045$ & $<0.045$ \\
\hline
\end{tabular}


Table 2 Q235A mechanics parameters

\begin{tabular}{cccccc}
\hline $\begin{array}{c}\text { Material } \\
\text { performance index }\end{array}$ & $\begin{array}{c}\text { Modulus of } \\
\text { elasticity/GPa }\end{array}$ & Yield strength/MPa & $\begin{array}{c}\text { Ultimate } \\
\text { strength/MPa }\end{array}$ & $\begin{array}{c}\text { Hardening } \\
\text { exponent }\end{array}$ & Elongation/\% \\
\hline Value & 200 & 363 & 490 & 0.245 & 16.1 \\
\hline
\end{tabular}

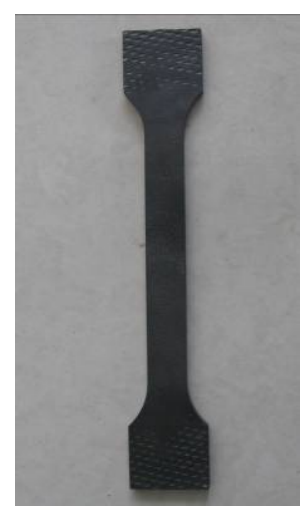

Before tensile test

Fig.1. Tensile specimens

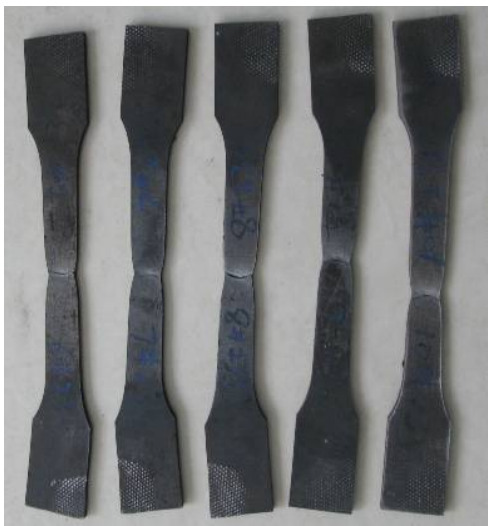

After tensile test

Table 3 Main technical parameters of hydraulic machine

\begin{tabular}{ccccccc}
\hline parameters & $\begin{array}{c}\text { Nominal } \\
\text { pressure/ }\end{array}$ & $\begin{array}{c}\text { Liquid } \\
\text { pressure/ } \mathrm{MPa}\end{array}$ & $\begin{array}{c}\text { The maximum closed } \\
\text { interval/mm }\end{array}$ & $\begin{array}{c}\text { Stroke } \\
/ \mathrm{mm}\end{array}$ & $\begin{array}{c}\text { Worktable size } \\
/ \mathrm{mm}\end{array}$ & $\begin{array}{c}\text { Working speed } \\
/(\mathrm{mm} / \mathrm{s})\end{array}$ \\
\hline Value & 3.15 & 25 & 1280 & 800 & $1220 \times 1220$ & 10 \\
\hline
\end{tabular}

The displacement and forming force were respectively measured by the displacement sensor of YY-WY200-75mm and the pressure sensor of YY-C129-20t as shown in Figure 3. The bending angles before and after springback were measured by the collecting of the point cloud using 3DSS grating scanner as shown in Figure 4. Fitting bending surface of sheet before and after spingback, conversing and processing the point cloud using reverse modeling software CATIA. The relationships between forming stroke, crimping width, step length and spingback angle, bending angle were analyzed.

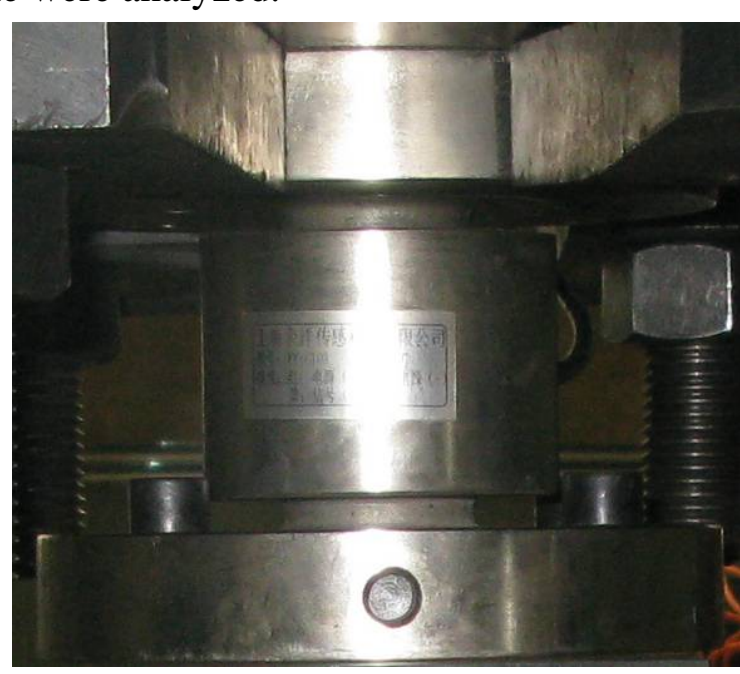

a) Pressure sensor

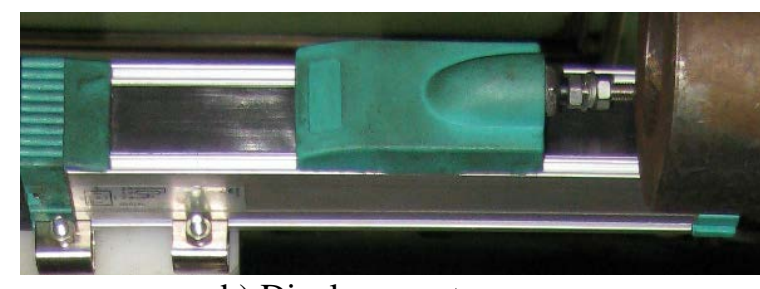

b) Displacement sensor

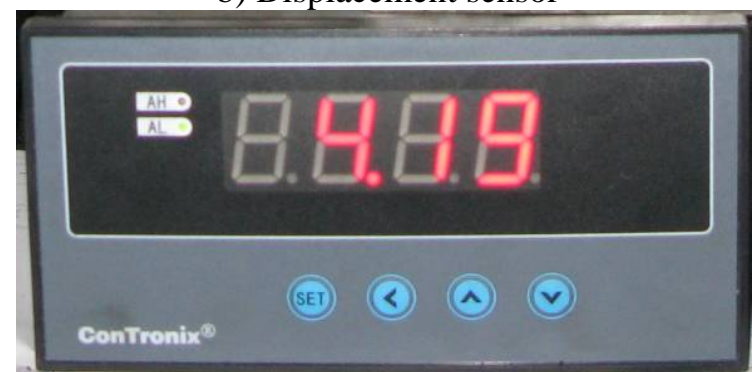

c) Digital display instrument

Fig.3 Measuring instruments used in the experiment 


\section{Experimental results and analysis}

Crimping experiment process and formed parts were respectively shown in Figure 5 and Figure 6 . Reference to the experimental model, the theorial calculation and finite element analysis were performed simultaneously. Though there are inevitable gaps between simulated results, calculated results and experiment results, the general regularity for the parameters is consistent. The analysis results were shown in Figure 7 to Figure 12.

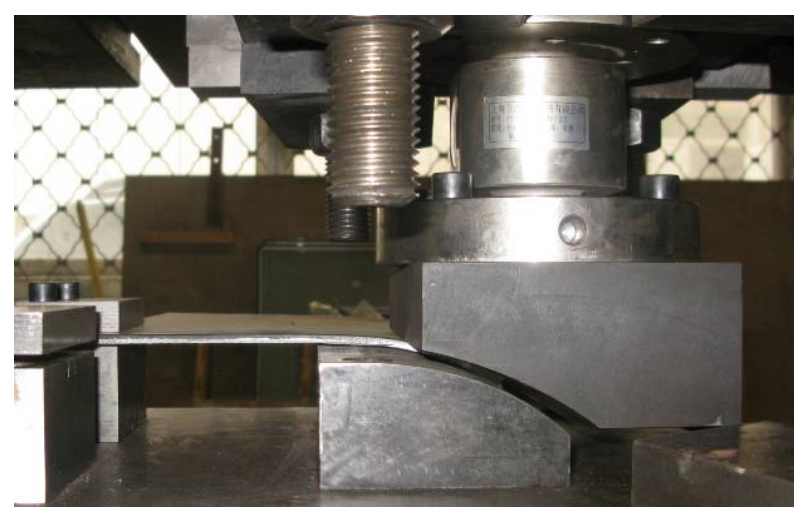

Fig.5 Crimping experiment

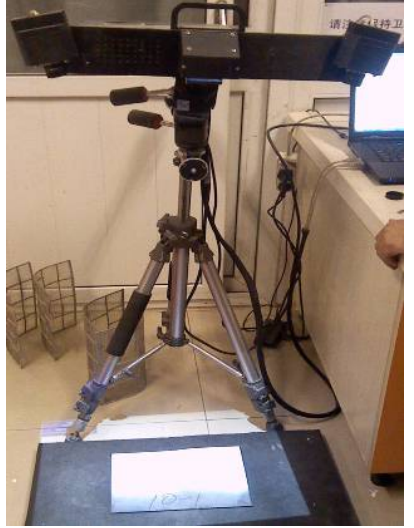

Fig.4 Three coordinate scanner

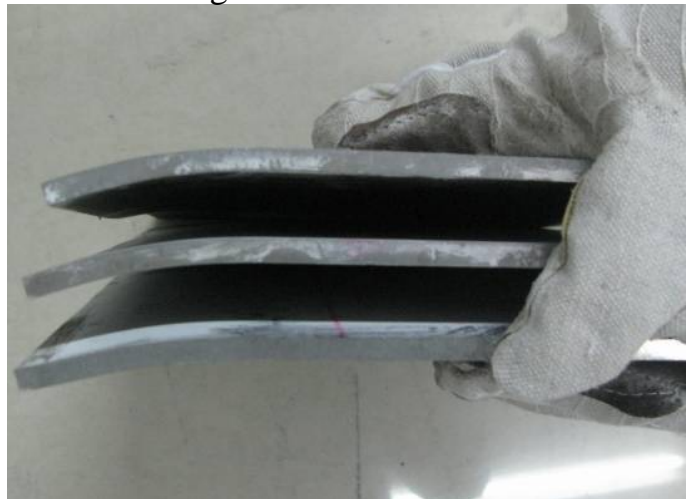

Fig.6 Formed parts

Figure 7 shows the relation between crimping die displacement and bending angle. With the displacement change of crimping die, plate bending angles before and after springback increase gradually approximated along linear. Compared to the experimental results and simulation results, the maximum relative error was $7.65 \%$ for bending angle before springback , $9.85 \%$ for bending angle after springback, $5.76 \%$ for bending angle before springback, $26.8 \%$ for bending angle after springback.

In Figure 8, the forming force changes upward with incresing of die displacement. The maximum relative error is $9.9 \%$ comparing to the simulation results and experimental results, $27.6 \%$ to theorial calculation results and experiment results.

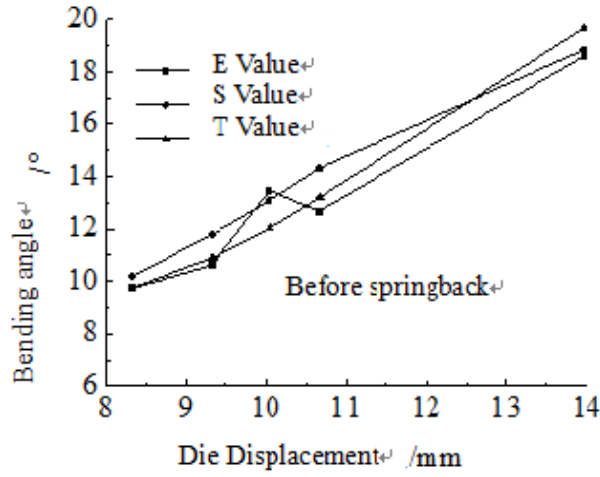

a)

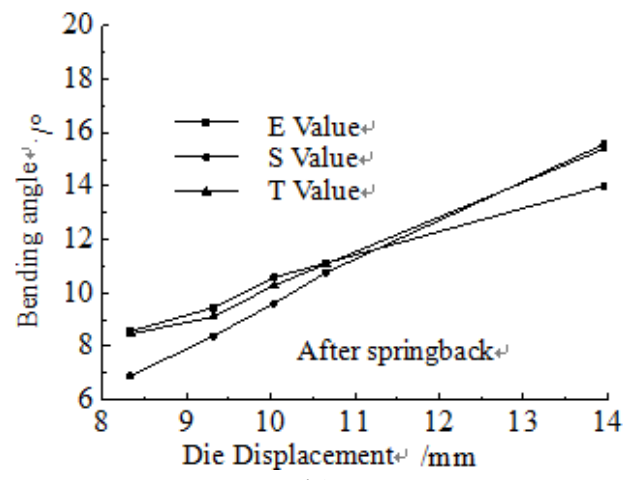

b)

Fig.7 Relation curves of the die stroke and bending angle 


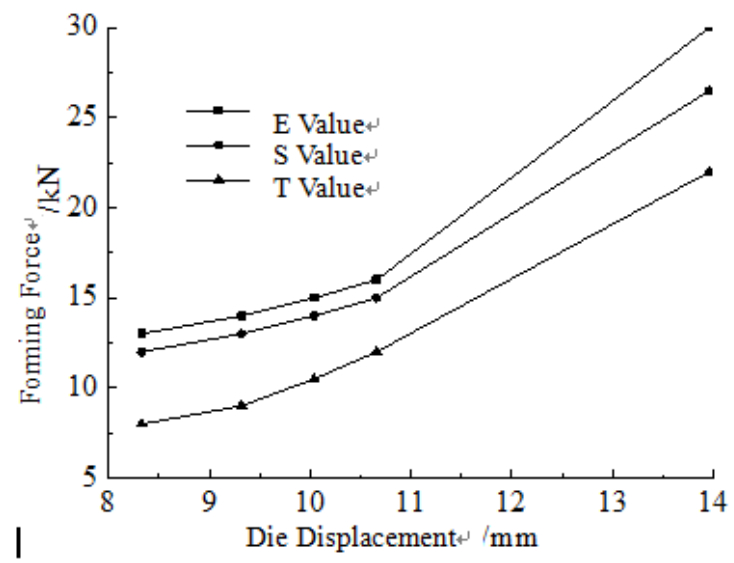

Fig.8 Relation curves of the die stroke and maximum forming force

Figure 9 shows the relation between crimping width and bending angle. The bending angle changes downward in a linear trend with increasing of die stroke. The maximum relative error is $2.3 \%$ for bending angle before springback, $2.9 \%$ for bending angle after springback between the simulation results and experimental results, 3.94\% for bending angle before springback, and 2.38\% for bending angle after springback between theorial calculation results and experiment results.

The forming force changes upward in a curve trend with increasing of crimping width as shown in Figure 10. The maximum relative error is $6.66 \%$ comparising to the simulation results and experimental results, $5.88 \%$ to theorial calculation results and experiment results.

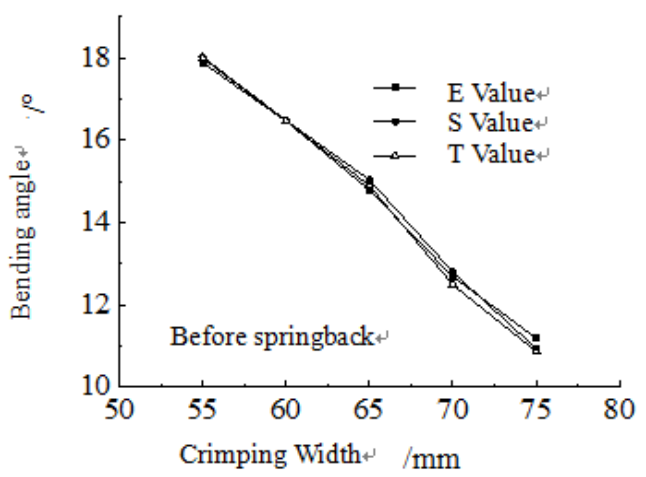

a)

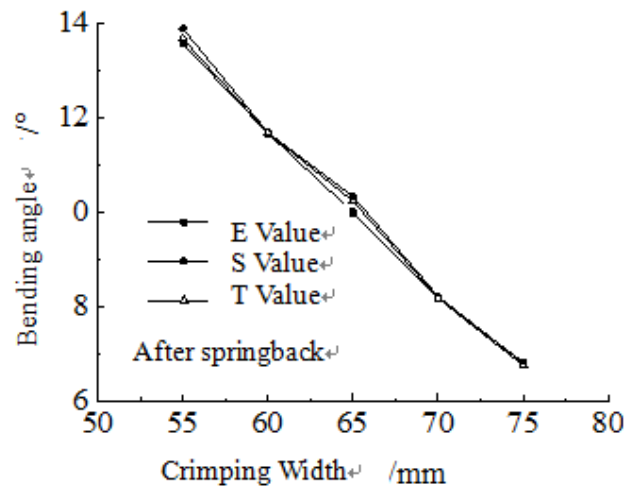

b)

Fig.9 Relation curves of the crimping width and the bending angle

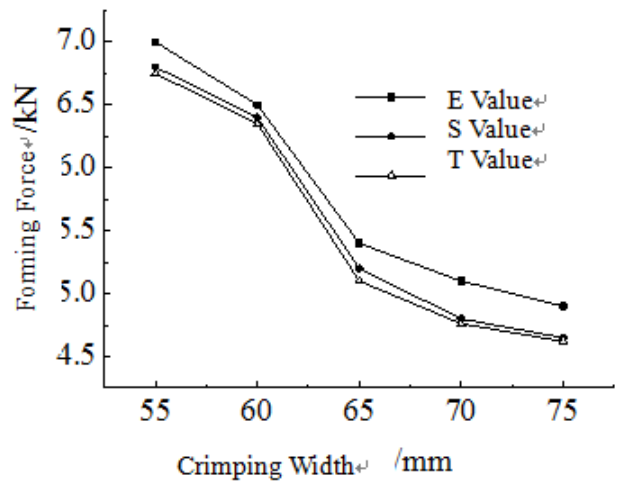

Fig.10 Relation curves of the crimping width and the maximum forming force

The relations between the step length and the bending angle are illustrated shown in Figure 11 . The maximum relative error is $5.08 \%$ before springback, $2.22 \%$ after springback comparing to the simulation results and experimental results, 3.79\% before springback, and $1.54 \%$ after springback comparing to theorial calculation results and experiment results.

The forming force changes upward in a curve trend with increasing of step length as shown in Figure 12. The maximum relative error is $3.37 \%$ comparing to the simulation results and experimental results, and $5.76 \%$ to theorial calculation results and experiment results. 


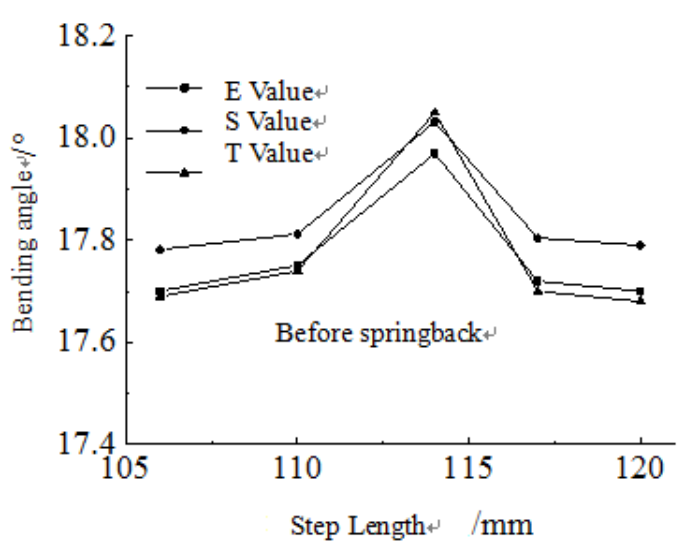

a)

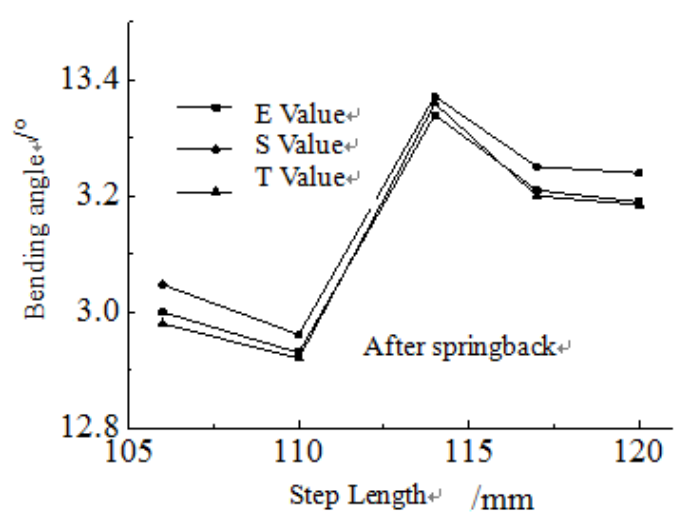

b)

Fig.11 Relation curves between the step length and the bending angle

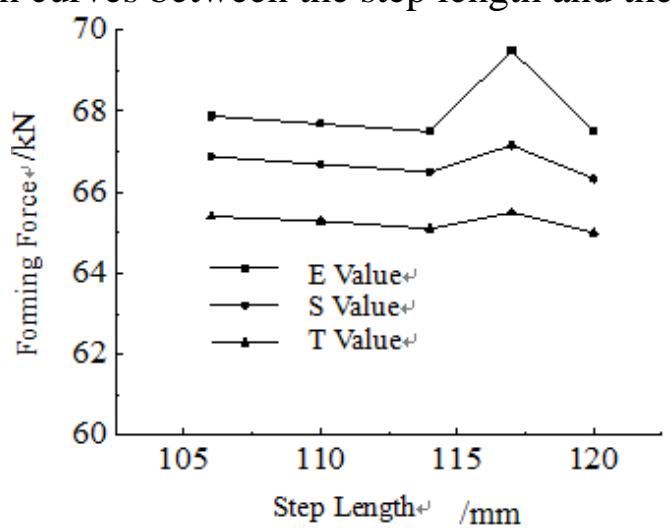

Fig.12 Relation curves between the step length and the maximum forming force

\section{Conclusion}

A large number of reduced crimping forming experiments of large diameter longitudinal welded pipe were performed. The experiment model is more close to the actual production. Relations between the die stroke, the crimping width, the step length and bending angle before and after springback are obtained. The results can be used to guide crimping parameters design and the actual production.

\section{Acknowledgement}

The authors are grateful for the financial support provided by the Doctor Foundation of Hebei University of Science and Technology, China (Grant No. QD201207), the Natural Science Foundation of Hebei Provincial Education Department, China (Grant No. Y2012035) and the Natural Science Foundation of Hebei Provincial Technology Department, China (Grant No. 12211014), the Scientific Research Projects of the Inner Mongolia Provincial Education Department (Grant No. NJZY14006).

\section{References}

[1] Hong Li. Prebending process of longitudinal submerged arc welding production line [J]. Welding Pipe and Tube, 2006, 29(1): 55-57(In Chinese)

[2] Jinglei Liu, Kcjian Huang, Feng Ruan. Effects of the parameters of prebending on O-forming of pipe in UOE process [J]. Journal of Plasticity Engineering, 2005, 12(3): 72-75(In Chinese)

[3] M. D. Herynk, S. Kyriakider, A Onoufriou, et al. Effects of the UOE/UOC pipe manufacturing processes on pipe collapse pressure. International Journal of Mechanical Sciences, 2007, 49(5): 533-553 
[4] Zhimin Xie, Jinming Xia. Prebending process parameter design of longitudinal submerged arc welding pipe [J]. Welding Pipe and Tube, 2007, 30(3): 52-54(In Chinese)

[5] Fan Lifeng, Gao Ying, Yun Jianbin. Analysis of crimping of large diameter welding pipe, Advanced Materials Research, 2014, 997: 517-521

[6] Qiang Yang. Springback analytic and process parameters optimization of plate edge preflex for the forming of large diameter longitudinal seam welded pipe[D], Yanshan university 2012(In Chinese)

[7] Lifeng Fan, Ying Gao, Qiang Li, Hongshen Xu, Quality Control on Crimping of Large Diameter Welding Pipe. Chinese Jounal of Mechanical Engineering [J]. 2012, 25(6): 1264-1273 